\title{
TWO WAY COMUNICATION BASED FAMILY EMPOWERMENT CONCEPT TO MAINTAIN THE ECONOMY AND WALFARE OF RETIRED TKI FAMILY AT ARJOWILANGON
}

\author{
Luluk Dwi Kumalasari \\ Muhammadiyah University of Malang
}

\begin{abstract}
Migration phenomenon by Indonesian migrant workers (TKI), bring significant influence toward the change of their family. Influence of this change within the family as the cause of migration, either bring the better economy and welfare or, a devastated and disorganized family. The effort to empower retired TKI family means to improve TKI family using existing resources, opportunity, skills and knowledge to elevate their household economy and welfare. However, there are still many cases of problematic TKI families, but there are also families that can manage their household income once they return home.

As the basis area of east java migrant workers, Malang Regency specifically Arjowilangun Village become one of the interesting locust to examine the case of TKI Family empowerment in order to ensure their security and welfare of their family based on two way comunication. The model of two way communication, certainly undeniable to achieve desirable outcome by family. This model used to deliberate case retired TKI family at Arjowilangun village.

This research attempt to elaborate the phenomenon of retired TKI Family whom able to manage their household income and improve their family welfare, by using the concept of TKI family empowerment to secure their household economy and family welfare based on two way comunicationmodel. The result of this research hope to serve the conceptual purpose or example for retired TKI family to enhance their economy and family welfare.

On empirical basis, the two way comunication model were effectively applied by the member of Retired TKI Family. Horizontally the outcome of this communication would create more relax and intimate. Other from that outcome, the economic enterprise with the involvement of retired TKI could stimulate the sustainable household income and further, the long term economic stability.
\end{abstract}

Keyword; security, welfare, Indonesian migrant worker, empowerment 


\section{PENDAHULUAN}

Banyak penelitian yang telah mengkaji tentang perpindahan penduduk dan pengaruhnya dengan kualitas dan ketahanan keluarga, diantaranya adalah penelitian yang dilakukan oleh Thomas \& Wilcox tahun 1987 dalam Sussman, yang menyebutkan bahwa perubahan sosial yang berlangsung cepat, industrialisasi dan urbanisasi dipandang sebagai faktor yang dapat menyebabkan disorganisasi dalam keluarga (Sunarti, 2006).

Begitu juga dengan fenomena migrasi yang dilakukan oleh tenaga kerja Indonesia (TKI), banyak membawa pengaruh terhadap perubahan keluarga. Pengaruh perubahan dalam keluarga akibat melakukan migrasi ke luar negeri tersebut, bisa menyebabkan ketahanan ekonomi dan kesejahteraan keluarga semakin bagus, atau sebaliknya keluarga TKI tersebut akan mengalami kehancuran atau disorganisasi.

Banyak diantara para TKI ketika kembali ke tanah air mereka mengalami kesulitan, karena tidak mampu mengelola pendapatan yang diperoleh dari luar negeri. Mereka membelanjakan atau menggunakan uang dalam waktu singkat, biasanya digunakan untuk kebutuhan konsumtif, misalnya membangun rumah, membeli kendaraan bermotor, membeli sawah, dan lain-lain. Sementara untuk kebutuhan keluarga selanjutnya tidak mereka pikirkan, sehingga mereka harus mencari pekerjaan lain lagi untuk melanjutkan kehidupan selanjutnya. Di sisi lain, tidak jarang banyak TKI yang kembali ke rumah dengan kondisi keluarga yang tidak utuh lagi, artinya suami atau istri sudah tidak mau lagi dengan pasangan akibat terlalu lama ditinggal akhirnya memiliki orang ketiga. Jika sudah terjadi masalah seperti ini keluarga akan berantakan, perceraian menjadi jalan keluar dan kesejahteraan keluarga tidak bisa lagi dipertahankan, anak-anak menjadi korban. Fenomena atas masalah ekonomi dan kesejahteraan keluarga TKI ini memerlukan perhatian tersendiri, agar masalah tidak semakin banyak, mengingat keluarga TKI di Indonesia jumlahnya cukup banyak. Meskipun begitu, masih ada keluarga TKI yang tidak mengalami masalah atau aman. Bagi keluarga yang mengalami masalah tentunya memerlukan upaya pemberdayaan untuk membangun ketahanan ekonomi dan kesejahteraan keluarga.

Upaya pemberdayaan bagi keluarga TKI Purna adalah mengupayakan keluarga TKI dengan menggunakan sumber daya, kesempatan, pengetahuan dan ketrampilan yang ada untuk meningkatkan dan mempertahankan ekonomi dan kesejahteraan demi kehidupan keluaraga mereka. Meskipun banyak keluarga TKI yang 
bermasalah, masih ada keluarga TKI yang hidup bahagia dengan pasangan dan mampu mengelola penghasilan dari luar negeri ketika kembali di tanah air. Penelitian ini akan mencoba untuk menggali lebih dalam terhadap keluarga TKI yang mampu mengelola ekonomi dan mempertahankan kesejahteraan keluarga, yaitu tentang bagaimana model pemberdayaan keluarga TKI dalam menjamin ketahanan dan kesejahteraan keluarga, melalui pendekatan two way comunication. Hasil penelitian ini diharapkan bisa menjadi model atau contoh bagi keluarga TKI yang lain untuk mempertahankan ekonomi dan kesejahteraan keluarga sepulang dari luar negeri.

Sebagai daerah yang menjadi basis tenaga kerja migran di Jawa Timur, daerah Kabupaten Malang khususnya Desa Arjowilangun menjadi menarik untuk dikaji dari segi pemberdayaan keluarga TKI dalam menjamin ketahanan dan kesejahteraan keluarga, yang berbasis two way comunication. Model komunikasi dua arah, tentunya tidak bisa dihindarkan dalam sebuah keluarga untuk mencapai tujuan yang diinginkan oleh pasangan. Model ini akan kami coba untuk melihat secara detail terhadap keluarga TKI di Desa Arjowilangun. Meskipun banyak ancaman terhadap ekonomi dan kesejahteraan keluarga TKI, namun masih ada keluarga-keluarga TKI yang mampu memiliki ketahanan ekonomi dan kesejahteraan keluarga. Melihat dari latar belakang yang telah di uraikan tersebut di atas, maka penelitian ini akan mengkaji permasalahan tentang bagaimana konsep pemberdayaan keluarga TKI purna berbasis two way comunication dalam mempertahankan ekonomi dan kesejahteraan keluarga di Desa Arjowilangun Kabupaten Malang. Tujuan dari penelitian ini adalah mengidentifikasi dan mendiskripsikan tentang: Konsep pemberdayaan keluarga TKI purna berbasis two way comunication dalam menjamin ketahanan dan kesejahteraan keluarga di Desa Arjowilangun Kabupaten Malang.

\section{METODE PENELITIAN}

Jenis penelitian dalam penelitian ini adalah adalah penelitian kualitatif dengan pendekatan fenomenologi. Pendekatan fenomenologi sengaja digunakan untuk mengungkap data abstrak dan simbolik dengan tujuan utama memahami gejala yang muncul sebagai sebuah kesatuan utuh, dengan memiliki konsep dasar kompleksitas realitas atau masalah 
yang disebabkan oleh perspektif subjek (Denzin, and Yvona S. Lincoln. 2000: 76).

Dalam menentukan subyek, peneliti menggunakan teknik snowball sampling. Sebagai informan pertama adalah keluarga ketua asosiasi TKI di desa Arjowilangun yaitu Bapak Mujianto. Sebelum menjadi ketua asosiasi TKI, beliau pernah menjadi TKI di Korea selama enam tahun. Saat ini dia telah kembali ke keluarganya di desa, dan mendirikan usaha percetakan, toko peralatan kantor dan fotografi keliling.

Metode Pengumpulan Data dalam penelitian ini menggunakan teknik wawancara dan observasi serta dokumentasi. Analisa data dilakukan dengan interpretasi berdasarkan makna fenomena sebagai upaya menjelaskan dan mendiskripsikan hasil penelitian. Selain itu, dalam analisis data juga digunakan metode refleksif, dimana refleksif dapat dilihat sebagai kesadaran atas diri dalam dimensi politik, kerja lapangan, dan konstruksi pengetahuan yang mencakup pemahaman serta interpretasi pengalaman dan diri subyek (Miles dan Haberman,1992).

Validitas menurut Lincoln \& Guba (1985) dalam Denzin \& Lincoln (2009) peneliti kualitatif bisa melakukan cek-silang temuan-temuan penelitian dengan partisipan dan langkah-langkah audit. Dalam membuat laporan naratif peneliti kualitatif bisa menggunakan orang lain (outsider) sebagai pembaca untuk melakukan cek dengan catatan-catatan lapangan (field notes) dan transkrip wawancara.

\section{HASIL DAN PEMBAHASAN}

Desa Arjowilangun adalah salah satu desa di Kecamatan Kalipare yang memiliki warga dengan tingkat migrasi (pergi ke luar negeri menjadi pekerja migran) cukup tinggi. Berdasarkan fakta ini, maka Desa Arjowilangun menjadi menarik untuk dikaji dari segi pemberdayaan keluarga TKI, terutama TKI purna dalam menjamin ketahanan dan kesejahteraan keluarga yang berbasis two way comunication (komunikasi dua arah), dengan judul konsep pemberdayaan keluarga berbasis two way comunication dalam mempertahankan ekonomi dan kesejahteraan TKI Purna. Model komunikasi dua arah, tentunya tidak bisa dihindarkan dalam sebuah keluarga untuk mencapai tujuan yang diinginkan oleh pasangan. Model ini akan kami coba untuk melihat secara detail terhadap keluarga TKI di Desa Arjowilangun. Meskipun banyak ancaman terhadap ekonomi dan kesejahteraan keluarga TKI, namun masih ada keluarga- 
keluarga TKI yang mampu memiliki ketahanan ekonomi dan kesejahteraan keluarga.

Dalam menentukan subyek, penelitian yang berjudul konsep pemberdayaan keluarga TKI berbasis two way comunication dalam menjamin ketahanan dan kesejahteraan keluarga ini, peneliti menggunakan teknik snowball sampling (bola salju yang biasa dilakukan secara menggelinding seperti bola). Sebagai informan pertama adalah keluarga ketua asosiasi TKI di desa Arjowilangun yaitu Bapak Mujianto. Sebelum menjadi ketua asosiasi TKI, beliau pernah menjadi TKI di Korea selama enam tahun. Saat ini dia telah kembali ke keluarganya di desa, dan mendirikan usaha percetakan, toko peralatan kantor dan fotografi keliling. Data dalam penelitian ini adalah data kualitatif tentang upaya pemberdayaan keluarga TKI dalam mempertahankan ekonomi dan kesejahteraan keluarga di Desa Arjowinangun.

Tabel 1

Daftar subyek penelitian

\begin{tabular}{|c|c|c|}
\hline no & nama & usia \\
\hline 1. & Sukesi & 54 tahun \\
\hline 2. & Yuliastri & 36 tahun \\
\hline 3. & Mujianto & 40 tahun \\
\hline 4. & Ishartatik & 40 tahun \\
\hline 5. & Sulis & 39 tahun \\
\hline 6. & Afifa & 35 tahun \\
\hline
\end{tabular}

Sumber; wawancara oleh peneliti

Hasil penelitian yang berupa data-data tentang konsep pemberdayaan, diperoleh dengan teknik wawancara dan observasi serta dokumentasi. Metode wawancara digunakan untuk memperoleh data tentang model pemberdayaan para keluarga TKI dengan berdasar two way comunication, data tentang upaya menjamin ketahanan dan kesejahteraan pasca pulang dari luar negeri. Semua wawancara yang dilakukan didukung dengan metode observasi. Sedang metode dokumentasi digunakan untuk mencari data-data sekunder yang berkaitan dengan TKI di Desa Arjowilangun. Sehingga data yang didapatkan di lapangan sangat jelas dan mudah untuk dipahami. 
Adapun hasil lapangan terkait dengan permasalahan penelitian yaitu bagaimana konsep pemberdayaan keluarga TKI purna berbasis two way comunication dalam mempertahankan ekonomi dan kesejahteraan keluarga di Desa Arjowilangun Kabupaten Malang, adalah sebagai berikut;

\section{A. Konsep pemberdayaan keluarga TKI purna berbasis two way communication.}

Pemberdayaan keluarga adalah upaya untuk meningkatkan kualitas keluarga, baik sebagai sasaran maupun sebagai pelaku pembangunan, sehingga tercipta peningkatan ketahanan fisik maupun non fisik, kemandirian serta kesejahteraan keluarga dalam rangka mewujudkan sumberdaya manusia yang berkualitas. Sedang kualitas keluarga adalah kondisi keluarga yang mencakup aspek pendidikan, kesehatan, ekonomi, sosial budaya, kemandirian keluarga, mental spiritual serta nilai-nilai agama yang merupakan dasar untuk mencapai keluarga sejahtera ( UU Nomor 52 Tahun 2009 Tentang Perkembangan Kependudukan dan Pembangunan Keluarga).

Konsep two way comunication adalah salah satu proses komunikasi dimana komunikasi dua arah merupakan komunikasi yang berlangsung antara dua pihak dan ada timbal balik baik dari komunikator maupun komunikan. Komunikasi dua arah dapat terjadi secara vertical, horizontal, dan diagonal. Dimana komunikasi vertikal adalah komunikasi yang alirannya berlangsung dari atas ke bawah atau sebaliknya. Dalam suatu perusahaan, komunikasi vertikal yang terjadi adalah komunikasi yang berlangsung antara manajemen tingkat atas, menengah, hingga ketingkat karyawan. Sedang komunikasi horizontal yang berlangsung antara komunikator dengan komunikan yang mempunyai tingkat, kedudukan, dan wewenang yang sama. Contohnya komunikasi antara karyawan yang satu dengan yang satu level. Serta komunikasi diagonal adalah komunikasi yang berlangsung antara komunikator dengan komunikan yang tingkat, kedudukan, serta wewenangnya berbeda.

Berdasarkan hasil wawancara yang dilakukan peneliti dengan subyek penelitian, konsep pemberdayaan keluarga TKI purna di Desa Arjowilangun dengan cara atau konsep komunikasi dua arah mayoritas bisa dikatakan berjalan atau dilakukan dengan 
baik. Komunikasi yang dilakukan lebih bersifat horizontal (tidak ada anggapan yang berlebih atau membeda-bedakan status atau peran mana yang lebih tinggi atau lebih rendah). Seperti hasil wawancara dengan bu Sukesi (mantan TKW dari Arab selama enam tahun, usia 54 tahun, lulusan SD, anak ada lima orang);

Saya dengan suami kalau mau bicara apa saja tentang keadaan keluarga kita ya langsung saja bu, kita biasa bicara apa adanya blak blakan saja, misalnya bicara tentang anak, sawah atau yang lainnya. Sama anak saya ya biasa saja, kalau mereka ada keperluan ya segera ngomong ke kita dan kadang saya atau bapaknya ya tanya-tanya.

Selain bu Sukesi, hal senada juga diuangkapkan oleh TKI purna yang lain yaitu bu Ishartatik (40 tahun, lulusan SMP, mantan TKW dari Hongkong selama empat tahun, anak dua);

Kalau saya bu dalam urusan anak dan menjalankan usaha kecantikan salon serta rias pengantin milik saya ya tetap sering berhubungan dengan suami melalui telepon, kan suami saya masih di Korea bu heee. Ya alhamdulilah suami tetap tanggung jawab dengan mengirimkan hasil kerjanya untuk saya dan anak-anak. Kalau ada masalah saya ya sering cerita, begitu juga suami saya. Ya yang sempat ya menelepon duluan gitu bu.

Keterbukaan untuk saling berbicara dan bercerita tentang masalah keluarga dan usaha yang dijalankan dari hasil bekerja di luar negeri juga diamini oleh pak Mujianto (40 tahun, mantan TKI di Korea selama enam tahun, anak 2, lulusan SMA), selaku ketua Koperasi yang beranggotakan mantan-mantan TKI.

Keterbukaan dengan pasangan dalam keluarga dan menjalankan usaha memang penting bu meski tanggungjawab nafkah lebih di suami heee. Saya sama istri ya terus berusaha untuk menerapkan dan menjaga cara bicara yang baik yang tidak bikin emosi. Apalagi saya sama istri sama-sama pernah bekerja di luar negeri, jadi kita benarbenar harus bisa menjaga dan mengelola hasil dari sana dengan baik untuk masa depan anak-anak kita. Saya harus selalu melihat ke diri saya sendiri untuk tetap baik bu, karena saya juga termasuk orang yang memediasi kelurga TKI yang masih di luar negeri dengan keluarganya yang di Desa sini agar kondisi keluarga tetap baik, agar mereka tetap saling percaya dan tidak gampang kemakan gossip bu heee. 
Secara umum kita dapat menyimpulkan bahwa dalam proses membuat keluarga para TKI purna menjadi berdaya (dalam menciptakan ketahanan ekonomi dan kesejahteraan keluarga), ternyata mereka sedikit banyak sudah memahami bahwa salah satu kuncinya adalah bicara dengan baik dan terbuka dengan sesama anggota keluarga, antara suami dengan istri atau antara orang tua dengan anak, dan ini menjadi hal yang penting. Selain itu mereka juga bisa saling bertukar cerita dan pengalaman melalui wadah koperasi yang memang khusus didirikan untuk para TKI purna, yang diketuai oleh bapak Mujianto.

\section{B. Ketahanan ekonomi dan kesejahteraan keluarga}

Ketahanan keluarga adalah kondisi dinamika suatu keluarga yang memiliki keuletan dan ketangguhan serta mengandung kemampuan fisik material dan psikis mental spiritual guna hidup mandiri, mengembangkan diri dan keluarganya untuk mencapai keadaan harmonis dalam meningkatkan kesejahteraan lahir dan batin (UU Nomor 10/1992). Pearsall (1996) dalam Herin (2012) menyatakan bahwa rahasia ketahanan atau kekuatan keluarga berada diantaranya pada jiwa altruism antara anggota keluarga yaitu berusaha melakukan sesuatu untuk yang lain, melakukan dan melangkah bersama, pemeliharaan hubungan keluarga, menciptakan atmosfir positif, melindungi martabat bersama dan merayakan kehidupan bersama.

Undang-Undang Nomor 10 Tahun 1992, keluarga sejahtera adalah keluarga yang dibentuk berdasarkan atas perkawinan yang sah, mampu memenuhi kebutuhan hidup material dan spritual yang layak, bertaqwa kepada Tuhan Yang Maha Esa, memiliki hubungan yang serasi, selaras dan seimbang antar anggota dan antar keluarga dengan masyarakat dan lingkungan. Taraf kesejahteraan tidak hanya berupa ukuran yang terlihat (fisik dan kesehatan) tapi juga yang tidak dapat dilihat (spiritual).

Ferguson, Horwood dan Beutrais (dalam Sumarwan \& Tahira (1993) menyatakan bahwa kesejahteraan keluarga dapat dibedakan ke dalam kesejahteraan ekonomi (family economic wellbeing) dan kesejahteraan material (family material well-being).

Berdasarkan konsep tersebut, peneliti dapat menjelaskan sesuai hasil wawancaa dengan subyek penelitian bahwa ketahan ekonomi dan kesejahteraan TKI purna di Desa Arjowilangun mayoritas bisa dikatakan berhasil, karena uang hasil kerja keras 
mereka selama di luar negeri tidak hanya habis untuk pemenuhan kebutuhan materiil atau konsumsi materiil sesaat (beli tanah atau sawah, memperbaiki rumah, beli kendaraan dan lain-lain), tetapi banyak yang bisa memanfaatkan atau mengelola untuk jangka panjang yaitu untuk usaha. Seperti yang mereka sampaikan melalui hasil wawancara berikut ini;

Sejak pulang dari Korea saya memang sudah berpikir dan memutuskan bu bahwa saya tidak akan pergi kerja lagi ke luar negeri, untuk itu maka saya harus benar-benar bisa menggunakan hasil kerja saya untuk hal yang punya manfaat seterusnya dan tidak habis dalam jangka waktu pendek, maka keputusan saya adalah saya harus usaha atau membuka lapangan kerja untuk keluarga saya. Maka berdasarkan kesepakatan saya dan istri usaha percetakan dan toko peralatan kantor yang kita pilih. Alhamdulilah bisa berjalan dengan baik. Kebutuhan sehari-hari bisa tercukupi, untuk kebutuhan anak juga bisa diatasi. Selain itu saya juga yang punya inisiatif mendirikan wadah koperasi bagi para TKI purna bu, ya agar harta mereka tidak habis dengan sia-sia dan bisa diputar untuk usaha (wawancara dengan Bapak Mujianto).

Pernyataan pak Mujianto juga dikomentari dengan baik oleh Bu Afifa (alm. Suami dulu kerja di Korea selama empat tahun, lulusan SMA, 35 tahun, anak 3). Beliau menyampaikan;

Benar bu kita ini memang harus berhati-hati dan sigap dalam mengelola hasil kerja keras keluarga kita di luar negeri supaya tidak habis dengan percuma, karena kerja di luar negeri itu lama bu bertahun-tahun heee. Hasil jerih payah almarhum suami saya saya gunakan untuk buka persewaan komputer dan video game serta toko mainan bu. Alhamdulilah meski suami saya telah tiada tapi kami yang ditinggalkan bisa menjalani hidup dan memenuhi kebutuhan kami dengan baik dari hasil usaha kami.

Mantan TKI purna yang lain yang juga ikut membuka usaha dari hasil kerjanya yaitu bu Ishartatik, kata beliau; Saya sama suami membuka usaha salon kecantikan dan rias pengantin bu. Alhamdulilah sama dengan TKI-TKI purna yang lain, usaha kami bias berjalan. Meski tidak setiap hari ada pesanan rias pengantin tapi dari hasil itu kami bias memenuhi kebutuhan kami, 
terutama untuk anak-anak kami. Kalau ada masalah kami juga bias gengan gampang cerita kemudian dibantu melalui koperasi.

Berbeda dengan Pak Mujianto, Bu Afifa dan Bu Ishartatik, mantan TKI purna yang lain yaitu Bu Sukesi, Bu Yuliastri dan Bu Sulis lebih memilih menggunakan hasil kerja mereka di luar negeri untuk beli tanah atau sawah. Meski tidak setiap saat atau setiap hari mendapatkan penghasilan, menurut mereka dengan bertani kebutuhan mereka juga tercukupi meski tidak berlebih. Yang penting diwujudkan kata mereka.

Komunikasi yang terjalin diantara para anggota keluarga TKI purna semuanya bersifat horizontal yang berlangsung antara komunikator dengan komunikan yang mempunyai tingkat, kedudukan, dan wewenang yang sama. Tidak ada konsep membedabedakan mana yang lebih berkuasa, mana yang lebih pintar dan lain sebagainya. Suami istri mempunyai wewenang dan kedudukan yang sama. Sangat jelas bahwa keuntungan dari komunikasi dua arah ini, apalagi bersifat horizontal, maka adanya dialog antara komunikator dengan komunikan berjalan dengan santai dan lancar, sehingga menimbulkan kepuasan diantara kedua belah pihak. Informasi yang diterima menjadi lebih jelas, lebih akurat dan lebih tepat, karena dapat diperoleh langsung penjelasannya. Memunculkan rasa kekeluargaan, kekerabatan, dan iklim demokratis. Menghindari kesalahpahaman.

Berdasarkan data hasil wawancara ini pemberdayaan keluarga TKI purna dengan membuka usaha atau bisnis ternyata bisa menjadi cara yang baik untuk menciptakan ketahanan ekonomi dan kesejahteraan keluarga. Realita di Desa Arjowilangun ini bias direkomendasikan untuk mantan-mantan TKI di daerah lain. Bahwa menjadi Tenaga Kerja ke luar negeri bukannlah suatu yang menakutkan dengan resiko besar akan tidak sejahteranya keluarga. Tetapi semua kekhawatiran itu bisa diatasi dengan cara komunikasi yang baik diantara anggota keluarga yang ada.

\section{KESIMPULAN DAN SARAN}

\section{KESIMPULAN}


Mengacu pada rumusan masalah yang ada, terkait dengan konsep pemberdayaan keluarga berbasis two way communication dalam mempertahankan ekonomi dan kesejahteraan keluargaTKI purna di Desa Arjowilangun Kecamatan Kalipare Kabupaten Malang, maka dapat disimpulkan bahwa; dalam proses membuat keluarga para TKI purna menjadi berdaya (dalam menciptakan ketahanan ekonomi dan kesejahteraan keluarga), ternyata mereka (para TKI Purna) sedikit banyak sudah memahami bahwa salah satu kuncinya adalah bicara dengan baik dan terbuka dengan sesama anggota keluarga, antara suami dengan istri atau antara orang tua dengan anak, dan ini menjadi hal yang penting. Selain itu mereka juga bisa saling bertukar cerita dan pengalaman melalui wadah koperasi yang memang khusus didirikan untuk para TKI purna, yang diketuai oleh bapak Mujianto.

Komunikasi yang bersifat dua arah dengan cara horizontal, adanya dialog antara komunikator dengan komunikan berjalan dengan santai dan lancar, menimbulkan kepuasan diantara kedua belah pihak. Informasi yang diterima menjadi lebih jelas, lebih akurat dan lebih tepat, karena dapat diperoleh langsung penjelasannya. Memunculkan rasa kekeluargaan, kekerabatan, dan iklim demokratis dan menghindari kesalahpahaman diantara anggota keluarga TKI purna.

\section{SARAN}

Berdasarkan hasil lapangan yang telah peneliti jelaskan, diharapkan hasil penelitian ini dapat bermanfaat sebagai wawasan bagi para calon TKI dan TKI purna di Indonesia, terutama wilayah Malang.

Para TKI diharapkan juga mempunyai pemikiran yang berbeda dan berubah ke arah yang lebih baik untuk penataan hidup dan masa depan mereka dalam pemanfaatan hasil kerja ke luar negeri tersebut.

Pemerintah melalui Dinas Tenaga Kerja seharusnya lebih sigap dalam menyikapi persoalan-persoalan yang dihadapi para TKI, sehingga mereka bisa bekerja dengan tenang dan nyaman tanpa kekhawatiran yang berlebih.

Wadah perkumpulan para TKI dan TKI purna memang harus ada sebagai sarana bersosialisasi dan berbagi ilmu dan pengalaman juga untuk usaha bersama, agar apa yang telah didapatkan bisa bermanfaat untuk jangka panjang.

Melalui kesempatan ini, kami sampaikan ucapan terima kasih kepada Rektor Universitas Muhammadiyah Malang, yang telah memberikan peluang dan menfasilitasi seluruh dosen pada lingkungan UMM untuk melaksanakan salah satu point Tri Darma Perguruan Tinggi, 
yakni penelitian internal. Ucapan terima kasih juga kami sampaikan kepada pimpinan DPPM-UMM yang telah mengkoordinir pelaksanaan Program Penelitian ini secara sistematis dan terbuka.

Ucapan yang sama kami sampaikan juga pada para TKI purna di Desa Arjowilangun Kalipare yang telah meluangkan waktunya untuk bercerita dan berbagi pengalaman tentang cara-cara yang dilakukan dalam mempertahankan ekonomi dan kesejahteraan keluarga. Atas kerja samanya selama kegiatan ini berlangsung, sekali lagi diucapkan terima kasih.

\section{DAFTAR PUSTAKA}

Denzin, Norman K. 2009. Hand Book of Qualitatif Research. Jakarta: Pustaka Pelajar

Faturrochman. 2001. Revitalisasi Peran Keluarga. Buletin Psikologi, Tahun IX, No.2 Desember 2001, 39-47

Gayle, V, etc. 2008. Family Migration and Social Stratification. International Journal of Sociology and Social Policy Vol. 28 No.78, 2008,293-303

John W.Creswell, 1998. Qualitative Inquiry and Research Design. SAGE Publication

Puspitawati, Herin. 2012. Gender dan Keluarga: Konsep dan Realita di Indonesia. PT IPB Press. Bogor.

Kuswarno, Engkus. 2009. Fenomenologi (Fenomena Pengemis Kota Bandung). Bandung: Widya Padjadjaran.

Miles, Matthew B. and A. Michael Huberman. 1992. Analisis Data Kualitatif Buku Sumber tentang Metode-metode Baru. Jakarta: UI Press.

Sunarti, E, dkk. 2006.Indikator Keluarga Sejahtera: Sejarah Pengembangan, Evaluasi, dan Keberlanjutannya. Bogor: Institut Pertanian Bogor

Sunarti, E, dkk. 2005. Ketahanan Keluarga, Manajemen Stres, Serta Pemenuhan Fungsi Ekonomi dan Fungsi Sosialisasi Keluarga Korban Kerusuhan Aceh. Jurnal Media Gizi dan Keluarga, Juli 2005, 29 (1) : 41-49

Sulistyowati, Tutik (1999), Makna Sosial dan Ekonomi Tenaga Kerja wanita bagi keluaraga dan masyarakat di Pedesaan. Universitas Muhammadiyah Malang.

-------, (2000). Dampak Sosial Psikologis Tenaga Kerja Wanita terhadap Keluarga. Penelitian DPPM. UMM.

Veithzal, Rivai. 2005. Manajemen Sumber Daya Manusia Dari Teori Ke Praktek. Jakarta: PT. Raja Grafindo Persada

-------, UU No.52 Tahun 2009 tentang Perkembangan Kependudukan dan Pembangunan Keluarga.

--------, Malang dalam Statistik, 2013. 